\title{
Small airway dysfunction is associated with poorer asthma control
}

\author{
To the Editor:
}

The clinical relevance of the small airways in persistent asthma has been gaining greater recognition in recent years [1]. Studies have shown that a significant proportion of asthmatics on standard treatment fail to achieve satisfactory asthma control. For example, in one study of 3421 asthmatic subjects who underwent guideline-driven dose titration with standard inhaled corticosteroids (ICS)/long-acting $\beta$-agonist (LABA) combination therapy over 1 year, only $41 \%$ achieved total control of their asthma while $71 \%$ were well controlled [2]. ANDERSON et al. [3] found a high prevalence of adult patients with persistent small airway dysfunction determined by impulse oscillometry (IOS) (assessed as the difference between the resistance at $5 \mathrm{~Hz}\left(R_{5}\right)$ and that at $20 \mathrm{~Hz}$ oscillation $\left.(R 20)\right)$ and spirometry (assessed as the forced expiratory flow at $25-75 \%$ of forced vital capacity $(\mathrm{FEF} 25-75 \%)$ ) across British Thoracic Society (BTS) treatment steps for asthma, many of whom had a preserved forced expiratory volume in $1 \mathrm{~s}$ (FEV1). This, in turn, suggests an unmet clinical need in terms of patients who may have a small airway asthma phenotype.

We therefore evaluated whether small airway dysfunction was associated with worse control in adult asthmatics with a preserved FEV1 $(>80 \%$ predicted). Spirometry and IOS measurements from unselected asthmatics referred from primary care who attended screening for clinical trials were linked to prescription data. The prescription data were obtained from the Tayside Health Informatics Centre (Dundee, UK), which links all community-dispensed prescriptions using a person's unique identifier, the Community Health Index. Spirometry and IOS measurements from asthmatics were linked to oral corticosteroid and short-acting $\beta$-agonist (SABA) use. We evaluated whether small airway dysfunction, defined as FEF25-75\% $<70 \%$, or peripheral airway resistance, defined as $R 5-R 20>0.07 \mathrm{kPa} \cdot \mathrm{L}^{-1} \cdot \mathrm{s}$, was associated with increased oral corticosteroid and SABA use. Oral steroid and SABA use 1 year prior and 1 year following the index measurements were determined, i.e. whether or not patients had an oral steroid prescription for an asthma exacerbation, or the use of more than four, or four or fewer SABA inhalers. Research ethics committee approval was obtained for all the studies for which the patients were being screened, and Caldicott Guardian approval was obtained to transfer the data to the Health Informatics Centre. IOS (Masterscreen IOS; Jaeger, Hochberg, Germany) was performed in triplicate in accordance with the manufacturer's guidelines. A SuperSpiro spirometer (Micro Medical Ltd, Chatham, UK) was used in triplicate in accordance with European Respiratory Society guidelines [4]. Logistic regression analysis was applied to calculate the odds ratios for steroid and salbutamol use in the different groups. Age, sex, ICS, LABA and leukotriene receptor antagonists (LTRA) use were all included as covariates to calculate the adjusted odds ratio and $95 \%$ confidence interval.

302 (68\%) out of 442 asthmatics had a preserved FEV1 (>80\% pred) (mean age: 40 years; mean FEV1: 97\% pred; median ICS dose: $800 \mu \mathrm{g}$; 42\% were taking LABA, $22 \%$ were on LTRA and 5\% were on theophylline). The proportion of patients at BTS treatment steps $1-4$ were $6.3 \%, 37.7 \%, 27.8 \%$ and $28.0 \%$, respectively. The results in table 1 show that persistent small airway dysfunction, defined by FEF $25-75 \%$ and $R 5-R 20$, was associated with a significantly increased likelihood of having worse long-term asthma control. The risk of having poorer control was greater when measurements of $\mathrm{FEF} 25-75 \%$ and $R 5-R 20$ were combined. However, adding in FEV1/FVC to the model did not appreciably improve the odds ratio compared to the combined outcome of $\mathrm{FEF} 25-75 \%$ and $R 5-R 20$ because $\mathrm{FEV} 1 / \mathrm{FVC}$ and $\mathrm{FEF} 25-75 \%$ were both highly correlated $(\mathrm{r}=0.82$, $\mathrm{p}<0.001$ ). When our analysis was corrected for factors including age, sex, ICS, LABA and LTRA, the adjusted odds ratios for $\mathrm{FEF} 25-75 \%$ and $R 5-R 20$ were similar. $R 5 \%$ pred $(\mathrm{n}=302)$ and resonant frequency $(\mathrm{n}=268)$, however, did not have a significant impact in determining asthma control. There were insufficient evaluable data to perform a meaningful analysis of reactance area $(A X)(\mathrm{n}=75)$. During the study period, in those with a preserved FEV1, there were a total of 14 emergency department visits and 33 hospital admissions for asthma exacerbations. However, these numbers were too small to perform a meaningful analysis.

Our results are similar to those of previously reported studies in asthmatic children by SHI et al. [5] who showed a significant difference between selected cohorts of controlled and uncontrolled asthmatic children for both FEF25-75\% and FEV1/FVC, while peripheral resistance $\left(R 5-R 20>0.15 \mathrm{kPa} \cdot \mathrm{L}^{-1} \cdot \mathrm{s}\right)$ and $A X$ $\left(>0.95 \mathrm{kPa} \cdot \mathrm{L}^{-1}\right)$ were equally predictive for detecting control. In a prospective follow-up study [6] of initially controlled asthmatic children, the same authors observed a significant difference in FEV1/FVC but 
TABLE 1 Odds ratios for small airway indices in 302 patients with forced expiratory volume in 1 s (FEV1) $>80 \%$ predicted

\begin{tabular}{|c|c|c|c|c|}
\hline & \multicolumn{2}{|c|}{ Crude } & \multicolumn{2}{|c|}{ Adjusted } \\
\hline \multicolumn{5}{|c|}{ FEF25-75\% $<70 \%(n=157)$ versus FEF25-75\% $>70 \%(n=145)$} \\
\hline Oral steroid use & $1.67(1.04-2.68)$ & 0.04 & $1.50(0.91-2.48)$ & 0.11 \\
\hline SABA use & $2.00(1.27-3.16)$ & 0.003 & $1.91(1.19-3.07)$ & 0.007 \\
\hline \multicolumn{5}{|c|}{ FEV1/FVC $<0.80(n=167)$ versus $F E V 1 / F V C>0.80(n=135)$} \\
\hline \multicolumn{5}{|c|}{$R 5-R 20>0.07 \mathrm{kPa} \cdot \mathrm{L}^{-1} \cdot \mathrm{s}(\mathrm{n}=135)$ versus $R 5-R 20<0.07 \mathrm{kPa} \cdot \mathrm{L}^{-1} \cdot \mathrm{s}(\mathrm{n}=167)$} \\
\hline Oral steroid use & $1.99(1.23-3.19)$ & 0.005 & $1.80(1.09-2.98)$ & 0.02 \\
\hline SABA use & $1.83(1.16-2.89)$ & 0.01 & $1.87(1.15-3.01)$ & 0.01 \\
\hline \multicolumn{5}{|c|}{$\begin{array}{l}\text { FEF } 25-75 \%<70 \% \text { and } R 5-R 20>0.07 \mathrm{kPa} \cdot \mathrm{L}^{-1} \cdot \mathrm{s}(\mathrm{n}=83) \text { versus } \\
\text { FEF } 25-75 \%>70 \% \text { and } R 5-R 20<0.07 \mathrm{kPa} \cdot \mathrm{L}^{-1} \cdot \mathrm{s}(\mathrm{n}=93)\end{array}$} \\
\hline Oral steroid use & $2.77(1.48-5.18)$ & 0.001 & $2.34(1.20-4.58)$ & 0.01 \\
\hline SABA use & $3.16(1.61-6.19)$ & 0.001 & $2.96(1.44-6.12)$ & 0.003 \\
\hline
\end{tabular}

FEF25-75\%: forced expiratory flow at $25-75 \%$ of forced vital capacity; SABA: short-acting $\beta$-agonist; FVC: forced vital capacity; R5: resistance at $5 \mathrm{~Hz}$; R20: resistance at $20 \mathrm{~Hz}$.

not $\mathrm{FEF} 25-75 \%$ at baseline, but for both FEV1/FVC and FEF25-75\% at follow-up after 3 months, comparing those who remained controlled with those who subsequently became uncontrolled. In a similar design to the present study, over 2 years, using electronic prescribing linkage, RAO et al. [7] compared matched groups of asthmatic children who had a preserved FEV1 ( $>80 \%$ pred), an abnormal FEV1/FVC $(<0.85)$ and FEF25-75\% $(<60 \%)$ with those with normal values, showing significantly increased odds ratios for loss of control in terms of oral steroid use, asthma exacerbations and controller use.

We elected to use cut-off thresholds for small airway measurements that provided the best compromise in terms of achieving balanced numbers of patients in each group from which to make informative comparisons. Such cut-off values for normality are always going to be rather arbitrary whether they are more or less severe in nature. We acknowledge our data have some limitations in terms of this being a retrospective-type health informatics study linked to a single index measurement of pulmonary function. However, we feel that our data more closely reflect real life practice, where compliance is usually poor in the community. Our unselected cohort of persistent asthmatics was referred from primary care and reflected a wide spectrum of severity across BTS treatment steps.

We feel that our study may have some important potential clinical implications. It appears that effortindependent (i.e. IOS) and effort-dependent measurements (i.e. spirometry) may provide distinct yet complimentary information on the small airway phenotype, as shown by the higher odds ratio for the composite of $\mathrm{FEF} 25-75 \%$ and R5-R20 compared with either measurement alone.

It remains unclear as to whether small airway markers may be improved by using extra-fine particle inhaled therapy, including currently available extra-fine ICS and ICS/LABA formulations, and how this relates to long-term asthma control. We also do not know whether small airway dysfunction, as reflected by abnormal FEF25-75\% or R5-R20, is due to ongoing persistent inflammation or simply altered airway geometry. Several prospective randomised controlled trials have shown greater improvements in small airway outcomes in response to extra-fine compared with coarse particle ICS formulations in unselected patient cohorts [8-12]. Other retrospective health informatics data comparing extra-fine and coarse particle ICS formulations have revealed consistent results in terms of improved asthma control based on prescribing outcomes, but have not measured any small airway pulmonary function outcomes [13-15]. We believe the time has now come for designing prospective randomised controlled trials enrolling patients with an enriched small airway phenotype, perhaps powered on pragmatic outcomes such as the Asthma Control Questionnaire. 
In conclusion, we have shown that in adult asthmatics who have a preserved FEV1, the presence of persistent small airway dysfunction was associated with poorer control, perhaps suggesting the presence of a defined small airway asthma phenotype.

0 @ERSpublications

In asthmatics with preserved FEV1, small airway dysfunction was associated with poorer long-term control http://ow.ly/yAWgY

Arvind Manoharan, William J. Anderson, Joseph Lipworth, Ibrahim Ibrahim and Brian J. Lipworth

Scottish Centre for Respiratory Research, Ninewells Hospital and Medical School, University of Dundee, Dundee, UK.

Correspondence: Brian J. Lipworth, Scottish Centre for Respiratory Research, Division of Cardiovascular and Diabetes Medicine, Medical Research Institute, University of Dundee, Ninewells Hospital and Medical School, Dundee DD1 9SY, UK. E-mail: b.j.lipworth@dundee.ac.uk

Received: April 112014 | Accepted after revision: June 152014 | First published online: July 172014

Conflict of interest: Disclosures can be found alongside the online version of this article at erj.ersjournals.com

\title{
References
}

1 Lipworth B. Targeting the small airways asthma phenotype: if we can reach it, should we treat it? Ann Allergy Asthma Immunol 2013; 110: 233-239.

2 Bateman ED, Boushey HA, Bousquet J, et al. Can guideline-defined asthma control be achieved? The Gaining Optimal Asthma ControL study. Am J Respir Crit Care Med 2004; 170: 836-844.

3 Anderson WJ, Zajda E, Lipworth BJ. Are we overlooking persistent small airways dysfunction in communitymanaged asthma? Ann Allergy Asthma Immunol 2012; 109: 185-189.

4 Miller MR, Hankinson J, Brusasco V, et al. Standardisation of spirometry. Eur Respir J 2005; 26: 319-338.

5 Shi Y, Aledia AS, Tatavoosian AV, et al. Relating small airways to asthma control by using impulse oscillometry in children. J Allergy Clin Immunol 2012; 129: 671-678.

6 Shi Y, Aledia AS, Galant SP, et al. Peripheral airway impairment measured by oscillometry predicts loss of asthma control in children. J Allergy Clin Immunol 2013; 131: 718-29.

7 Rao DR, Gaffin JM, Baxi SN, et al. The utility of forced expiratory flow between $25 \%$ and $75 \%$ of vital capacity in predicting childhood asthma morbidity and severity. J Asthma 2012; 49: 586-592.

8 Busse WW, Brazinsky S, Jacobson K, et al. Efficacy response of inhaled beclomethasone dipropionate in asthma is proportional to dose and is improved by formulation with a new propellant. J Allergy Clin Immunol 1999; 104: $1215-1222$.

9 Goldin JG, Tashkin DP, Kleerup EC, et al. Comparative effects of hydrofluoroalkane and chlorofluorocarbon beclomethasone dipropionate inhalation on small airways: assessment with functional helical thin-section computed tomography. J Allergy Clin Immunol 1999; 104: S258-S267.

10 Nicolini G, Chetta A, Simonazzi A, et al. Both bronchial and alveolar exhaled nitric oxide are reduced with extrafine beclomethasone dipropionate in asthma. Allergy Asthma Proc 2010; 31: 85-90.

11 Cohen J, Postma DS, Douma WR, et al. Particle size matters: diagnostics and treatment of small airways involvement in asthma. Eur Respir J 2011; 37: 532-540.

12 Juniper EF, Price DB, Stampone PA, et al. Clinically important improvements in asthma-specific quality of life, but no difference in conventional clinical indexes in patients changed from conventional beclomethasone dipropionate to approximately half the dose of extrafine beclomethasone dipropionate. Chest 2002; 121: 1824-1832.

13 Price D, Martin RJ, Barnes N, et al. Prescribing practices and asthma control with hydrofluoroalkanebeclomethasone and fluticasone: a real-world observational study. J Allergy Clin Immunol 2010; 126: 511-518.

14 Barnes N, Price D, Colice G, et al. Asthma control with extrafine-particle hydrofluoroalkane-beclometasone vs. large-particle chlorofluorocarbon-beclometasone: a real-world observational study. Clin Exp Allergy 2011; 41: $1521-1532$.

15 Colice G, Martin RJ, Israel E, et al. Asthma outcomes and costs of therapy with extrafine beclomethasone and fluticasone. J Allergy Clin Immunol 2013; 132: 45-54.

\section{Reduced lung function and the risk of out-of-hospital sudden cardiac death}

\author{
To the Editor:
}

Although some previous studies have shown that reduced lung function is related to cardiovascular mortality little is known about the relationship between lung function tests and the risk of sudden cardiac death (SCD) among the general population [1-5]. This prospective population-based study was designed to 